\title{
Daily and seasonal deformations of a Dutch Levee along a tidal river and during dry and wet conditions
}

\author{
Meindert Van ${ }^{1, a}$, Andre van Hoven ${ }^{1}$ and Michiel van de Ruyt ${ }^{1}$ \\ ${ }^{1}$ Deltares, PO Box 177, NL2600MH Delft, the Netherlands
}

\begin{abstract}
Along the river 'Hollandse IJssel' in The Netherlands two infiltration test have been executed. In both situations the levee is infiltrated over a stretch of 30 meters by a maximum overflow of $1.8 \mathrm{l} / \mathrm{m} / \mathrm{s}$. Dutch design criteria assume that up to a wave overtopping discharge of $1 \mathrm{l} / \mathrm{m} / \mathrm{s}$ the infiltration at the polder site of the levee will not significantly influence the level of the phreatic line in the levee. In both test the phreatic line is measured during several hours of overflow and infiltration, as well as some days before and after the experiment. During the test also horizontal and vertical deformations of the slope are measured. Daily and tidal deformations due to low and high tides were measured and show that the dike moves horizontally in the order of 2 to $4 \mathrm{~mm}$ during each tidal cycle. During overflow in the second test at the end of a dry summer, the levee also swelled and deformations up to $60 \mathrm{~mm}$ were measured. In this paper the two tests, the water pressure and deformation measurements and conclusions are presented.
\end{abstract}

\section{Introduction}

Along the tidal river 'Hollandse IJssel' in The Netherlands two infiltration test have been executed. In both situations the levee is infiltrated over a stretch of 30 meters by a maximum overflow of $1.8 \mathrm{l} / \mathrm{m} / \mathrm{s}$. The aim of the tests was to study the influence of wave overtopping and overflow on the phreatic line in the levee.

In the design of levees the influence of overtopping on the phreatic line is unsure and therefore conservative assumptions are made. In case of a wave overtopping of 1 $1 / \mathrm{s} / \mathrm{m}$ or more it is assumed in Dutch legal levee assessment guidelines that the levee is fully saturated for the macro stability assessments. In these guidelines assumptions are made. When assessing the macro stability of the landward levee slope, Dutch guidelines suggest no effect of wave overtopping when the discharge does not exceed 1 l/s per $\mathrm{m}$ and a fully saturated levee when $1 \mathrm{l} / \mathrm{s}$ per $\mathrm{m}$ is exceeded. Both criteria are very uncertain.

In both tests the horizontal and vertical deformations of the slope of the levee are measured during and after periodic overflow and infiltration. During the test the water pressures in the levee are also measured. In the first test the daily and tidal deformations due to low and high tides are measured. During overflow in the second infiltration test at the end of a dry summer, the levee swelled and deformations were measured representing seasonal deformations during summer and winter. In this paper the two tests are described briefly and references to the factual reports are given. The deformation measurements are presented in more detail.

\section{Infiltration test I and daily tidal deformations}

On Saturday August 19th, 2017 an infiltration test along the river 'Hollandse IJssel' was executed. In Figure 1 the test location is shown.

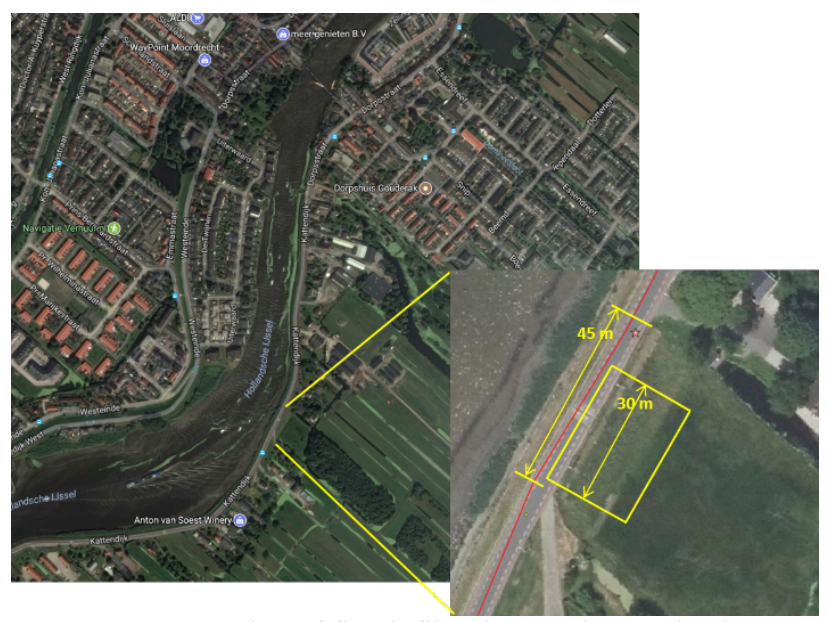

Figure 1 Location of first infiltration test in Gouderak.

The clay levee is situated on peat and clay subsoil layers above a sand layer. The cross-section of the levee is shown in figure 2. 


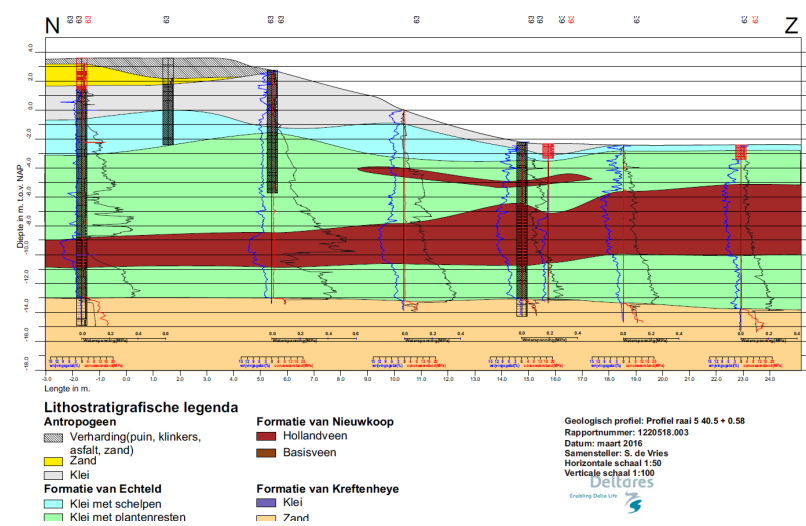

Figure 2 Cross-section of first infiltration test in Gouderak; Legenda: clay levee (grey layer) on clay (blue and green) and peat (brown) subsoil with a sand (orange) layer underneath.

Before the test pore pressure transducers were placed in the clay and peat layers. The results of these measurements are not the aim of this paper and therefore a reference is made to the factual report (A. van Hoven and A.F. Noordam, 2017b)

On Friday August 18 th, 2017 the infiltration tube and pumps were installed, see figure 3. During testing of this system an instability occurred, see figure 4 .

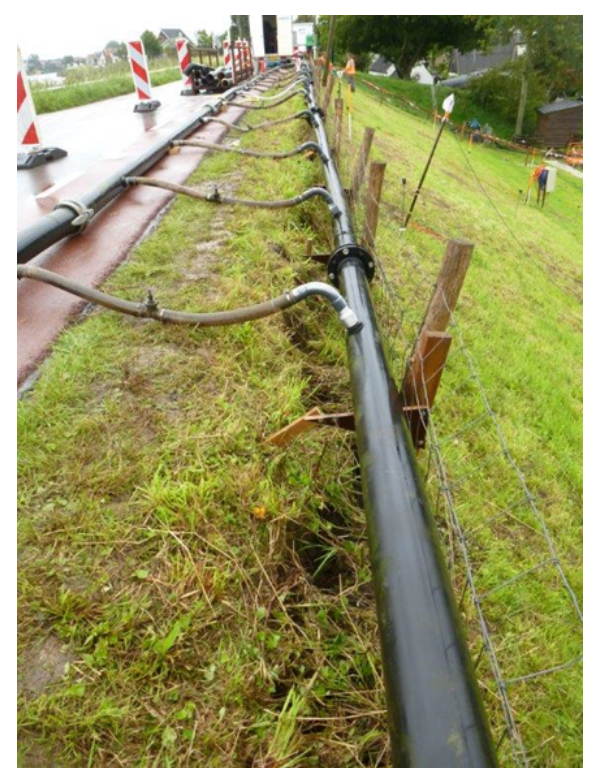

Figure 3 Infiltration tube on crest.

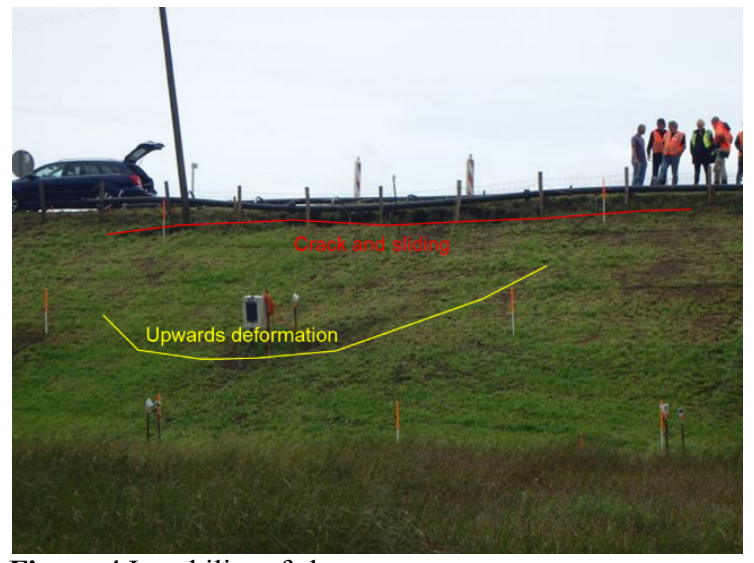

Figure 4 Instability of slope.
During the test the deformations were measured with total stations. In figure 5 the configuration of these measurements is shown. In 7 cross sections (called Raai 1 to 7 ) and on 4 points (called Punt 1 to 4 ) on the dike the deformations were measured.

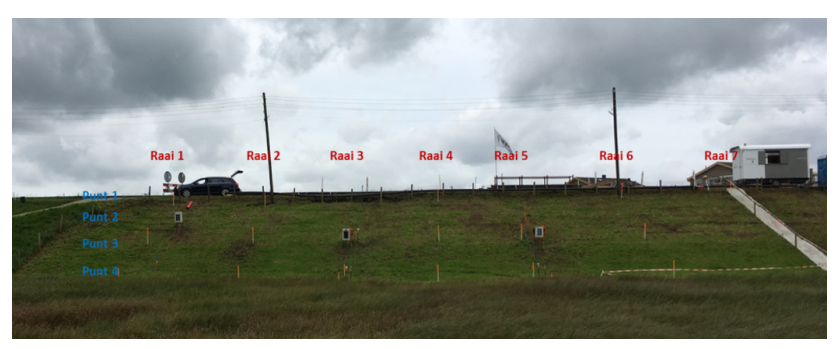

Figure 5 Location of measuments in Raai 2 and Point 1 to 4 on the slope.

De horizontal deformation in Raai 2, which is just left of the instability, is measured in the period after the instability. The measuments start circa 1 hour after the instability occurred. The measured horizontal deformation is presented in figure 6 .

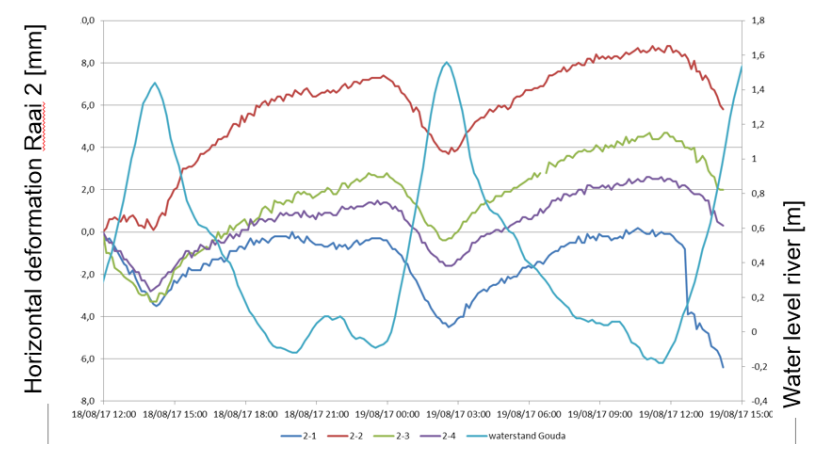

Figure 6 Horizontal deformations of 4 points in Raai 2 (mm) and water level river (blue line) $[\mathrm{m}]$.

In this period the tidal river fluctuates around 1.8 meter (top-top) while the levee moves horizontally around 3 to 4 $\mathrm{mm}$. It is concluded that roughly when the water level of the river moves up or down by $1 \mathrm{~m}$, the dike moves elastically horizontally around $2 \mathrm{~mm}$ horizontally. This daily elastic behavior of the levee is probably in the relatively soft clay and peat subsoil layers.

Due to the instability the test was stopped and the second test, described in the next section, on another location was planned.

\section{Infiltration test II and seasonal dry-wet deformations}

On June 27th and 28th of 2018 a second infiltration test was executed on a levee along the Hollandse IJssel a few kilometers south of the first experiment. The location is shown in figure 7. 


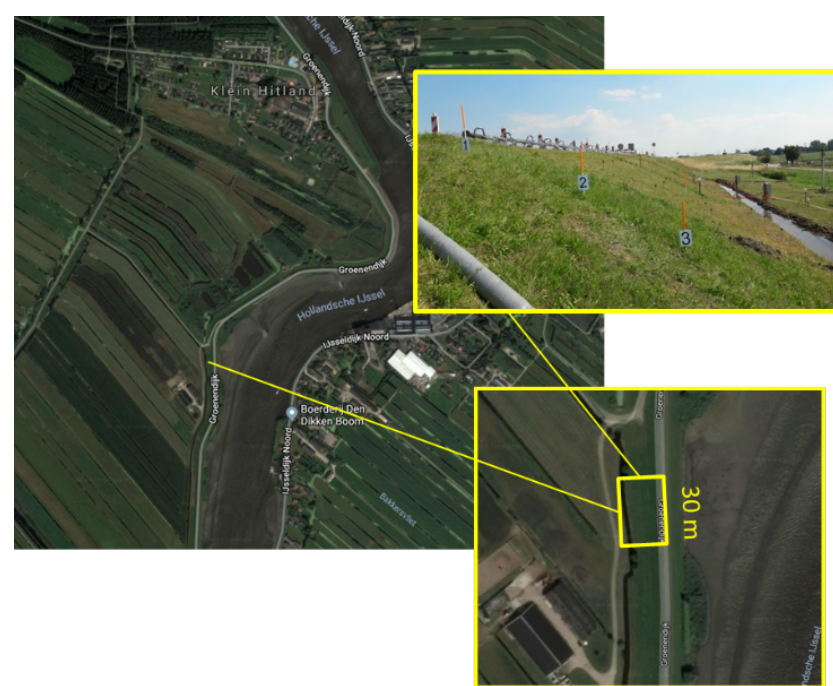

Figure 7 Lokation infiltration test II near Nieuwerkerk aan den IJssel.

The cross section is given in figure 8 . The slope has an angel 1:2. The crest is $4 \mathrm{~m}$ high (NAP $+4 \mathrm{~m}$ ) and has a berm with a length of $15 \mathrm{~m}$ and height level of 0 to $-1 \mathrm{~m}$ NAP, where NAP indicates the average sea level. The polder surface at the toe of the berm is around NAP - $2 \mathrm{~m}$, which is 2 meter below average sea level.

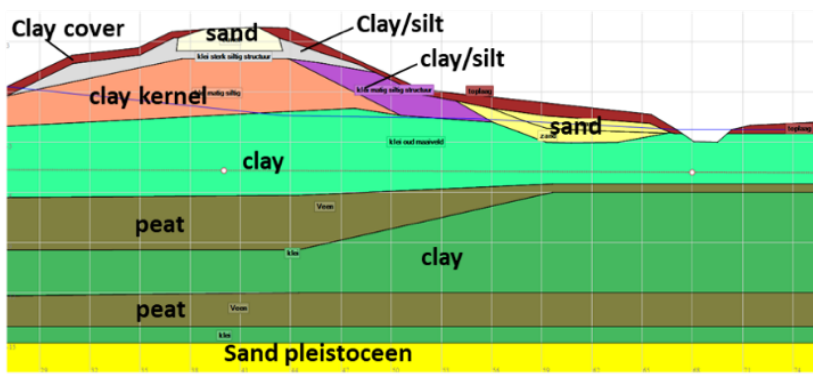

Figure 8 Cross section infiltration test II

Results of the test are described in a factual report (M. van der Ruyt, 2018). The measurements were performed in the test section of $30 \mathrm{~m}$ in 2 cross sections on a distance of $10 \mathrm{~m}$ : raai 1 and 2. Furthermore, raai 1 is at 10 meter distance from the southern boundary and raai 2 at $10 \mathrm{~m}$ from the northern boundary. In each of the cross sections the same configuration, see figure 9, of water pressure transducers and tensiometers were installed. The tensiometers are placed in the unsaturated zone above the phreatic line during daily conditions. The water pressure transducers in the saturated zone. The configuration of water pressure transducers and tension meters in both cross sections, called Raai 1 and Raai 2, are similar.

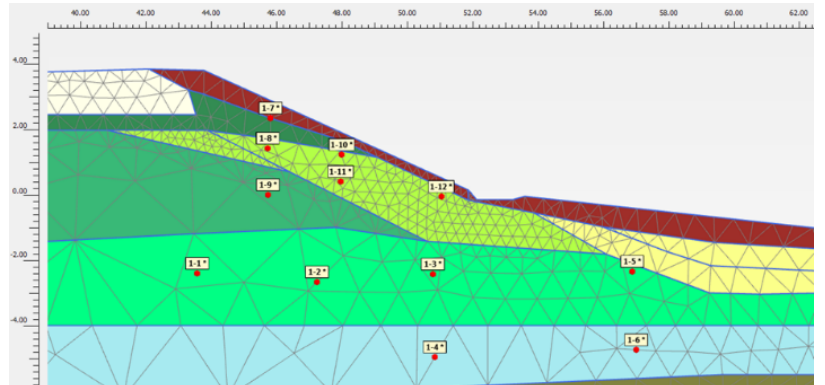

Figure 9 Cross section infiltration test II with tensiometers (which are the upper 6 and numbered 1-7 to 1-12) and water pressure transducers vwp's (the deeper 6 and indicated by 1-1 to 1-6); the first ' $1-$ ' stands for the cross-section 'Raai 1'.

Before the infiltration test started the water pressure transducers were installed. Due to a very dry summer the test started on June 25th and 26th with a 3.5 hour period of artificial rainfall on both days. In total a volume of around $30 \mathrm{~m} 3$ was rained on the slope of the section of $30 \mathrm{~m}$, which is equivalent to a circa $50 \mathrm{~mm}$ per day precipitation for 2 days. The 2-day overflow test started on Wednesday 27 June 2018. The sequence of pumping is given in table 1. The first day has pumping intervals and the second day continues overflow. On the second day a continues overflow of 10 hour is representative for a realistic storm in this area with typical design overflow conditions during 3 to 6 hours. During the test the deformations and water pressures were measured.

\begin{tabular}{|l|l|l|l|}
\hline Number & $\begin{array}{l}\text { Q } \\
\text { (overflow) } \\
\text { 1/s per m }\end{array}$ & on & off \\
\hline I & 0,19 & $08: 11$ & $08: 21$ \\
\hline II & 0,28 & $08: 55$ & $09: 14$ \\
\hline III & 0,37 & $09: 50$ & $10: 00$ \\
\hline IV & 0,37 & $10: 58$ & $11: 28$ \\
\hline V & 0,51 & $13: 01$ & $14: 31$ \\
\hline VI & 1,11 & $15: 15$ & $15: 50$ \\
\hline VI & 1,85 & $15: 50$ & $16: 45$ \\
\hline $\begin{array}{l}\text { June 28th } \\
\text { VII }\end{array}$ & 1,85 & $08: 00$ & $18: 00$ \\
\hline
\end{tabular}

Table 1. Overflow sequence June $27^{\text {th }}$ and $28^{\text {th }}$.

Predictions of the stability of this section did show a probability of $50 \%$ for failure in case the levee would be fully saturated. The daily river level is higher than the polder level since the polder is below sea level. Therefore, the first pumping day has overflow intervals to better understand the real behaviour of this levee. Also, the measurements were real-time used to monitor the stability during the test, since the levee was not allowed to fail. And in case of emergency a contractor was stand by for immediate repair measures. 


\subsection{Water pressures}

During the test all tensiometers in the upper part of the levee show a relatively quick rise. On day 2 , during the 10 hours overflow, most tensiometer pressures stabilize already after 1 hour see Figure 10 and 11 . In the figures, red indicates the overflow test periods as given in Table 1.

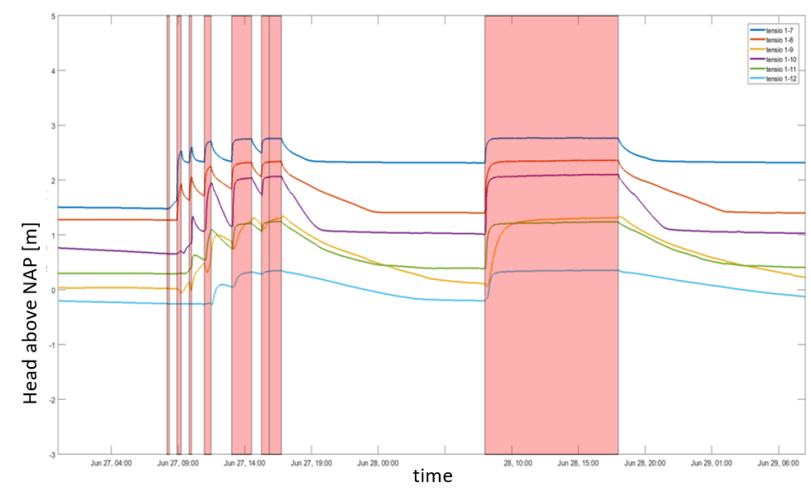

Figure 10 Head in tensiometers in levee in raai 1 as function of time.

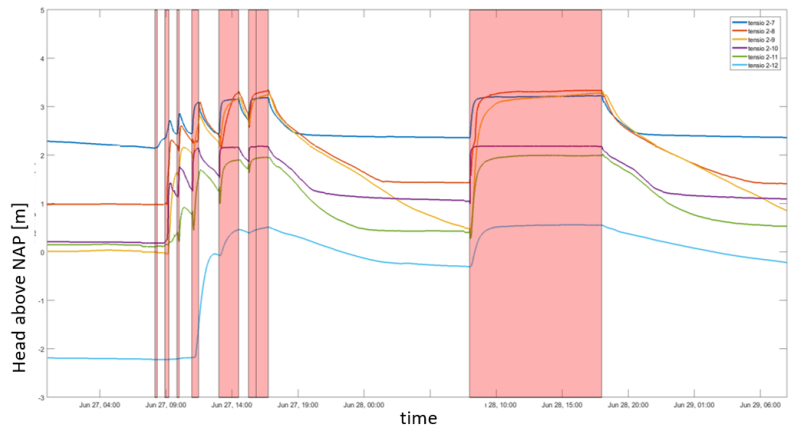

Figure 11 Head in tensiometers in levee in raai 2 as function of time.

A relatively quick reaction in the tensiometers are measured in both cross sections. This is probably caused by a relatively high permeability down to a depth of 2 to 3 meter. Only small periods of water infiltration are necessary to increase the water pressures.

There is a difference in the reaction measured in raai 1 compared to raai 2 . In raai 2 the water pressures are more or less hydrostatic up to surface level, which shows an almost fully saturated levee. In raai 1 only tensiometer 110 indicates a fully saturated levee. The other measurements in raai 1 are lower than hydrostatic pressures.

The deep tensiometer shows in raai 2 (tensiometer 2-9) a head for a fully saturated levee, but in raai 1 the same located tension meter (1-9) shows a head of NAP $+1,27 \mathrm{~m}$ which is almost $2 \mathrm{~m}$ below surface, which indicate an unsaturated zone of 2 meters dept. The reaction of the tensiometer 2-9 is as quick as 1-9, but its measured end value in raai 1 is much lower than in raai 2 .

From the measurements in these 2 cross sections it is concluded that the heterogeneity for infiltration in this levee is substantial. Also, the measurements in raai 2 show unexpectedly that the design guidance of 'no influence on the phreatic line in case of overflow is less than $11 / \mathrm{m} / \mathrm{s}^{\prime}$, is not conservative in that cross section.
The measurement at the start of the test show not significant higher phreatic line in the middle of the levee compared to the toe. Normally due to rainfall and low permeabilities, this bulge in the phreatic line is assumed. This already indicates a high permeability downto larger depth in the levee. Probably by biological activities and weather influences there are cracks or other small features that increase the permeability. Lab tests on the clay show much lower, up to a factor 1000 , permeabilities. Also tests on large diameter samples $(0.5 \mathrm{~m}$ by $1.0 \mathrm{~m})$ showed smaller permeabilities. It is concluded that in this cross section the levee is much more permeable then found in the lab tests (A. van Hoven and A, Noordam 2017b) and (M. van der Ruyt, 2018).

In the subsoil layers under the levee, water pressure transducers were installed. The results of these measurement are shown in figure 12 and 13 for Raai 1 and 2 respectively.

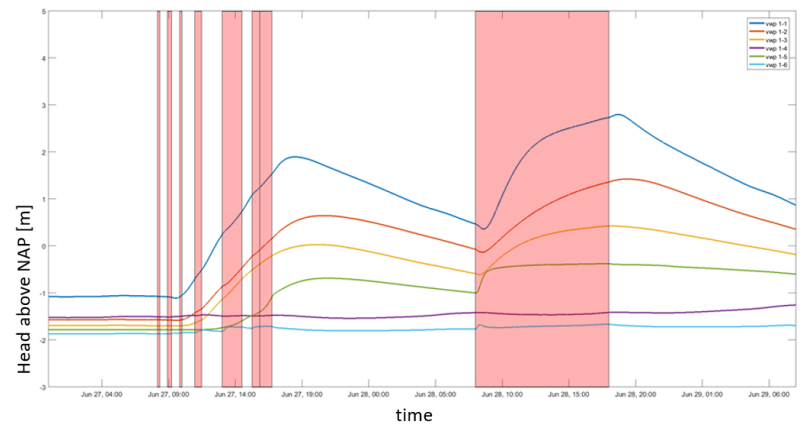

Figure 12 Head water pressure transducers subsoil in Raai 1 as function of time.

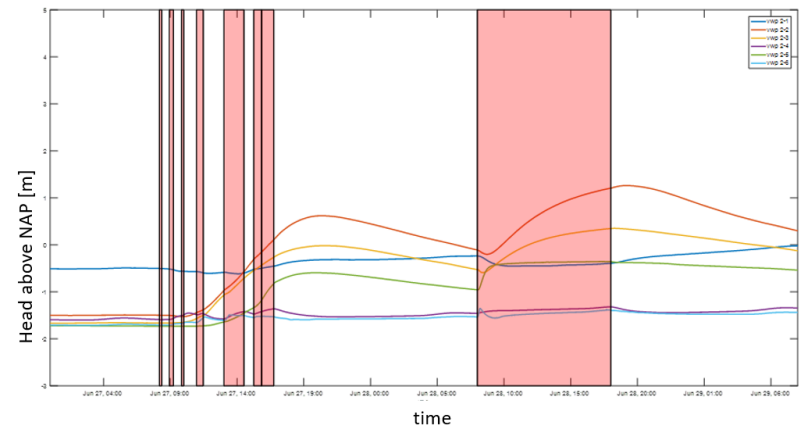

Figure 13 Head water pressure transducers subsoil in Raai 2 as function of time.

These deeper located water pressure transducers show as expected a slower response on the infiltration at the top of the slope. Before the start of infiltration these water pressures indicate the phreatic line during daily response of the river. This is in general a straight line between the average river level on the IJssel of circa NAP $+0.3 \mathrm{~m}$ and the average head in the polder of NAP $-2.25 \mathrm{~m}$. As already mentioned no significant bulge is seen in the phreatic line below the crest.

The deep water pressure transducers, which were mainly installed to monitor stability of deep sliding circles during the test, show a minimal response of around $0,1 \mathrm{~m}$. 
The higher located water pressure transducers show a substantial response during infiltration, and its maximum value is measured is after the end of the infiltration periods.

The water pressure tranducers under the levee (1,2 and 3) do not show a fully saturated levee within the period of infiltration. The quickest response is measured in the water pressures transducer 1 (vwp 1-1) in Raai 1, with a head of around $1 \mathrm{~m}$ below surface measured a few hours after the end of infiltration. In Raai 2 this water pressure transducers (vwp 2-1) is declining during the infiltration period on day 2 with also its maximum after the infiltration period. In Raai 2 water pressure transducer 2 (vwp 2-2) gives the fastest response, up to a head circa 1,5 $\mathrm{m}$ under surface.

In the deeper water pressure transducers it is the other way around with the higher water pressures measured in Raai 1 compared to Raai 2.

The measurements in both cross-section are not equal, while from the soil testing including borings and CPTs as well as electromagnetic (EM) testis was found that the levee was relatively homogeneous (M. van der Ruyt, 2018).

In the sand berm the water pressures become hydrostatic from the surface in both cross-sections. On the second day during the 10 hours infiltration the sand berm is saturated within a few hours.

Based on the measurements it is concluded that within a time period of a few hours, so within a design storm period, and a wave overtopping larger than $1 \mathrm{l} / \mathrm{s}$ per $\mathrm{m}$, the levee kernel above the daily saturated zone can become fully saturated. However, the influence on larger depth are not yet hydrostatic, but it is unsure how quick that process of infiltration to larger depth will be, because it is also dependent on cracks canals, for instance due to biological activity or to wet material or not fully compacted layers during construction, that transport the water pressure down to the deeper layers.

\subsection{Deformations}

For the measurement of the deformation of the slope during infiltration 60 prisma's were installed as shown in figure 14. Four total stations performed the measurements during the infiltration days. The aim of these measurements were mainly for monitoring the stability of the slope, since this levee was not allowed to fail. However, the measurements also show the deformation behavior of the levee during infiltration after a very dry summer period.

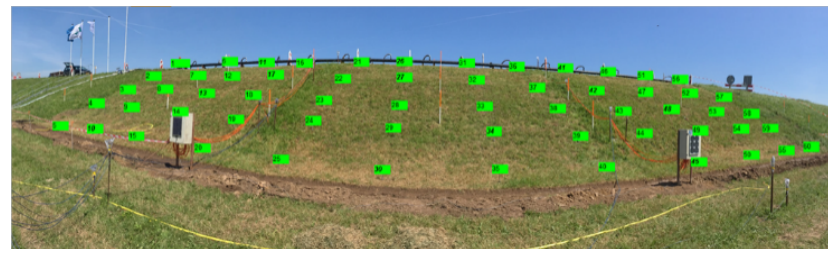

Figure 14 Location of the 60 measurement points of prisma's on the slope.

The measured deformation as function of time are shown in figure 15 and 16. In figure 15 and 16 respectively the horizontal and vertical deformation of the second row from the crest of the levee are shown along the $30 \mathrm{~m}$ test section.

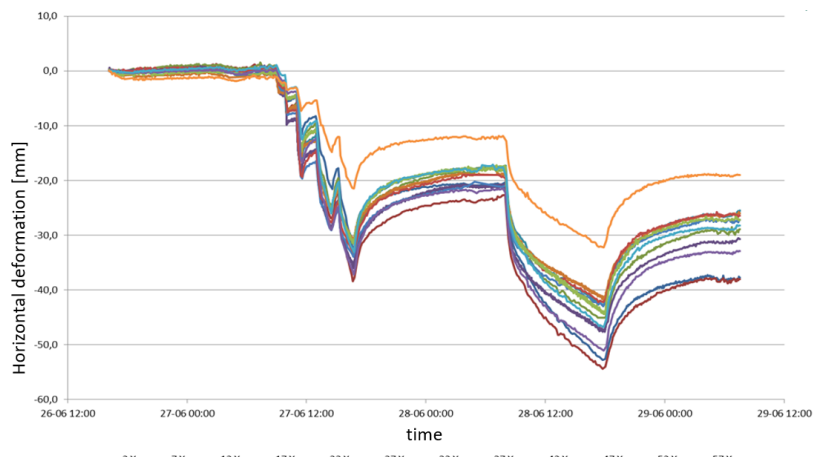

Figure 15 Horizontal deformation perpendicular to the levee (y-direction) in the second row from the crest; negative values are swelling deformations in the direction of the polder.

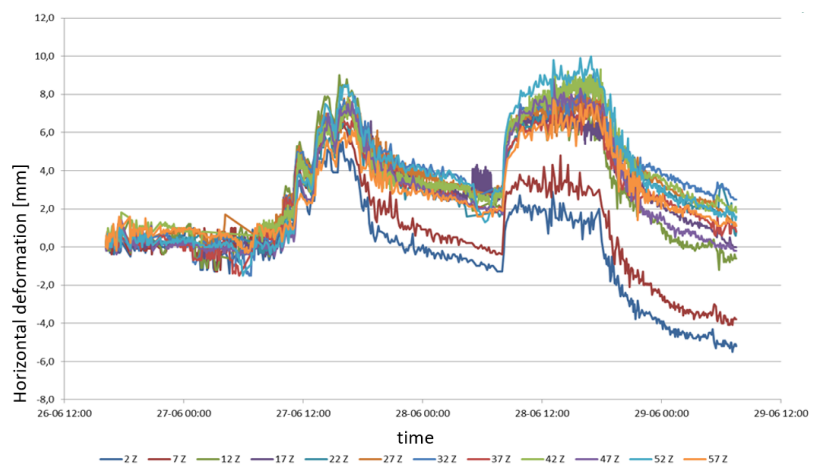

Figure 16 Vertical deformation (z-direction) in the second row from the crest; negative values are swelling deformations upwards.

The deformation is largely elastic behaviour and partly irreversible deformation. It reacts quickly after the start of infiltration.

Before the 2 infiltration days, small deformations were measured in a similar order as in the test I, which can be caused by the tidal behavior. However, these deformation measurements might be influenced by the artificial rain in the same period.

Some vertical deformations could have been caused by the weigth of the water. The saturated soil increases in weigth and due to partly unsaturated layers this could lead to some settlements. However, in the measurements swell is seen, so the effect of swell is substantially larger then setllements due to weigth increase.

\section{Conclusions}

In both tests the phreatic line is measured during several hours of overflow and infiltration. During the test the water pressures in the levee were measured. Based on the measurements it is concluded that within a time period of a few hours, so within a design storm period, and a wave overtopping larger than $1 \mathrm{l} / \mathrm{s}$ per $\mathrm{m}$, the levee kernel above the daily saturated zone can become fully saturated. However, the influence on larger depth are not yet 
hydrostatic, but it is unsure how quick that process of infiltration to larger depth will be, because it is also dependent on cracks canals, for instance due to biological activity or to wet material or not fully compacted layers during construction, that transport the water pressure down to the deeper layers.

In the tests, also horizontal and vertical deformations of the slope were measured. In the first test the daily and tidal deformations due to low and high tides are measured and show that the dike moves horizontally in the order of 2 to $4 \mathrm{~mm}$ during each tidal cycle. During overflow in the second test at the end of a dry summer, the levee also swelled and deformations up to $60 \mathrm{~mm}$ were measured.

Before the test started the stability of the levee was calculated with average strength parameters. For the second test and in case the levee would saturate, the calculation gave a Bisshop's stability factor of 1.0. During this second test no indications of stability loss were seen or measured. Due to this observation a new assessment for this levee has been performed. An updated probability of failure of the levee during the extreme conditions were calculated (M. van der Ruyt, 2018). This resulted for a safety assessment for this levee in terms of a probability of failure: a decrease of circa $1 / 75$ per year to circa $1 / 8500$ per year. It is concluded that these tests are valuable for insight, but also for an optimal assessment.

\section{Acknowledgements}

Both test program was led by Deltares and financed by a research program called POVM (project overarching research), which is a research program granted by the HWBP (high water protection program). The test was executed in cooperation with two water authorities, namely: 'Hoogheemraadschap van Schieland en de Krimpenerwaard' and the 'Waterschap Rivierenland'. The measurements were performed by Deltares, Infram and IV Infra.

\section{References}

1. A. van Hoven and A.F. Noordam, (2017a), POVM Beter benutten actuele sterkte KIJK Predictie Infiltratieproef IJsseldijk (in Dutch), August 2017, version 3, Deltares project number 11200643-000GEO-0007.

2. A. van Hoven and A.F. Noordam (2017b), POVM Beter benutten actuele sterkte KIJK Analyse Infiltratieproef IJsseldijk (in Dutch), November 2017, version 3, Deltares project number 11200643-000GEO-0009.

3. M. van der Ruyt (2018), POVM Infiltratieproef II, Factual report Infiltratieproef II langs de Groenendijk te Nieuwerkerk ad IJssel (in Dutch), Augustus 2018, version 1, Deltares project number 11202663-000GEO-0016. 